\title{
Bringing Federal Documents to the Forefront for Library Users: Selective Cataloging Using an OPAC
}

\author{
Victor T. Oliva
}

This article reviews the value of federal depository document titles, often underutilized as sources of research, and discusses reasons why many of them are worth cataloging. Several approaches to cataloging these titles to make them more readily accessible are profiled. The Adelphi University Library has devised a system, relying on Boolean logic and using an online public access catalog (OPAC), to choose which depository titles are worth cataloging because of their scholarly research value. This has resulted in the enrichment and expansion of the collection of readily available research titles and has contributed significantly to the library's permanent collection development program.

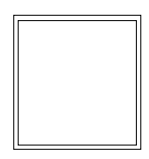
ne important and inexpensive source of information for library users in a college, a university, or a research library is that of depository titles received from the Government Printing Office (GPO). Federal depository libraries may receive a large range of titles that vary in size (e.g., one-page flyer or poster to a multivolume set) and quality. Adelphi University Library devised a system using an online public access catalog (OPAC) to catalog depository titles of scholarly research value. As a result, access to readily available sources of information was improved and a significant contribution to the library's permanent collection development program was made. Federal depository titles, immense and yet vastly underutilized sources of scholarly research, were thus brought to the forefront in the library's OPAC and to the attention of library users.
In this article, a review of the professional literature shows why federal depository titles should be more readily accessible in a library's OPAC. Various approaches to cataloging, including downloading all depository titles and choosing specific ones, are critiqued. Two unorthodox approaches to improving access to federal documents also are reviewed. In addition, the experience of Adelphi University Library in grappling with this problem is evaluated in detail. Based on this experience, it is strongly recommended that depository libraries carefully choose significant federal depository titles for inclusion in their OPAC.

\section{Review of the Professional Literature}

A review of the professional literature suggests a continuing trend to make federal depository titles more readily accessible to library users. The first question to address is why these materials are

Victor T. Oliva is Coordinator of Reference Services and Documents Reference Librarian in the Adelphi University Library; e-mail: oliva@adelphi.edu. 
worth acquiring. Marilyn K. Moody argued that government documents should be the source of first resort for research on any topic. ${ }^{1}$ Sometimes the first place

\section{Given the fact that federal docu- ments are an important source for academic and research libraries, a second question is how to make them more readily accessible.}

that information is published and distributed is in government documents. Research on some subjects of vital interest to the public, for example, may be essential and yet not commercially viable for private publishers. Another consideration is the fact that for some subjects the expertise and the funding available in government agencies are unavailable in the private sector. Thus, using the information in government publications is worth the consideration of serious researchers.

Given the fact that federal documents are an important source for academic and research libraries, a second question is how to make them more readily accessible. In an article on the importance of cataloging government documents, published in 1989, Mary Redmond characterized this notion as moving them from the backwater to the mainstream. ${ }^{2}$ She argued that federal documents cannot be exploited to their full potential unless they are cataloged and accessible through an online catalog. Redmond reviewed the advantages and disadvantages of three methods of accomplishing this:

- direct loading of tapes from the Monthly Catalog of United States Government Publications;

- contracting with a vendor to use these same data;

- individual cataloging using the OCLC database.

The problem with the first two options above is that they would include all titles available rather than focus on the titles the librarian actually feels are worth cataloging. The third option, selectively cataloging federal depository titles, requires a greater financial and staff com- mitment than some libraries are willing to make. (This option is addressed in some detail later in this article.) Redmond also pointed out that other alternatives are available, such as online access through DIALOG or BRS and through CD-ROM access. Alternative online access is problematic because it includes all items available, as opposed to the ones that a selective depository actually receives. Moreover, it would include woefully outdated titles that a library already may have discarded because the Monthly Catalog in electronic format covers publications as far back as 1976 and most selective depositories do not keep them much longer than five years.

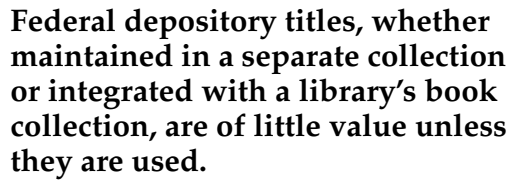

In addressing the issue of how to develop a collection development policy for government documents, Stanley P. Hodge, Diane Calvin, and Galen E. Rike discussed the importance of improving their accessibility. ${ }^{3}$ Federal depository titles cover a broad range of subjects and are a rich source for research but, unfortunately, are overlooked and underutilized by both library users and the librarians who serve them. Integrating documents into a library's cataloged collection would increase their visibility and thus their utilization. Even if federal depository titles are maintained in a separate collection, the wealth of information they contain can be exploited if they are cataloged.

Federal depository titles, whether maintained in a separate collection or integrated with a library's book collection, are of little value unless they are used. In an article discussing the organization of depository titles, Naomi V. Kerze addressed this issue. ${ }^{4}$ Prior to 1976 , when AACR rules and cataloging became available for use in the Monthly Catalog, it would have been prohibitively expensive 
to catalog all or a large portion of depository titles. If documents are kept separate and are not cataloged, they are less likely to be used. Library users may not know they need a document title for their research unless an index or a catalog leads them to it. Documents may be accessible through a paper index, but a paper index is less likely to be used than a catalog (which includes both books and documents). Thus, the documents still may be underutilized. Kerze showed that document titles in a card catalog (i.e., one that includes both books and depository titles) will be used more heavily. It also should be noted that after library users are led from a catalog to a specific document title, they are inclined to look for and find related titles there. When using an OPAC, library users are likely to search by subject, and if the depository title can be found there, it is more likely to be used. Kerze concluded that with bibliographic access to depository titles in an online catalog, the debate over separate-versusintegrated documents collections has become irrelevant.

The positive impact of bringing federal depository titles into the "bibliographic mainstream" by cataloging them was affirmed by Liz C. Alexander. ${ }^{5}$ She argued that GPO inspectors have strongly encouraged depository libraries to do so. She also reported that all studies have shown the positive impact of cataloging documents in terms of increased circulation, interlibrary loan, and in-house use. The value of a federal depository collection is confirmed and enhanced by its use.

\section{Approaches to Accessing Government Publications}

Accepting the premise that being able to find depository titles in an OPAC is critical to making library users aware of their existence, several strategies have been initiated to reach this goal. One possible approach is to match a library's holdings against GPO tapes, retrospectively cataloging them and making them OPAC accessible. Three articles on this approach have described both the problems en- countered and the benefits attained. In her 1990 article, Margaret T. Mooney noted that accurately matching the holdings of her selective depository library at the University of California-Riverside against GPO tape records was a serious concern. ${ }^{6}$ Ultimately, it was decided to match the complete SuDoc number of each and every title received against these records. Mooney concluded that this proved to be an inexpensive and nearly perfect method of cataloging all federal depository titles received in her library.

In a second article, Myrtle Smith Bolner and Barbara Kile argued that the GPO/ MARC tapes of GPO records are of such poor quality that they cannot be used for retrospective conversion. ${ }^{7}$ To make them usable, the authors established a consortium of document librarians at universities in Louisiana and Texas to work with a commercial vendor to clean them up and make them available to interested depository libraries as the MARCHIVE Tapes. Bolner and Kile concluded that there was a quantum leap in the use of federal depository titles in the libraries that used the tapes.

The impact of downloading GPO retrospective cataloging records into a library's OPAC, especially on reference librarians, was reviewed by Thomas Kinney and Gary Cornwell in a related third article published in $1991 .{ }^{8}$ After outlining the problems encountered, they nevertheless argued that it is worthwhile because it results in a much-needed increase in access to federal depository titles.

Unfortunately, the full retrospective cataloging approaches outlined in those three articles share two major drawbacks:

- They would result in the inclusion of all document titles a library has received.

- It is costly to include all the cataloging for all the titles.

It is questionable whether unselectively including the more ephemeral document titles in the public catalog is worthwhile. (This issue is addressed more fully in an- 
other section of this article.) The cost of fully processing all document titles received for cataloging is obviously much higher, and possibly prohibitively so for many libraries, than the cost of critically evaluating and selectively cataloging some GPO titles.

Some libraries have used more unorthodox approaches to access their depository collections. In a 1991 article, Douglas J. Ernst and Fred C. Schmidt argued for the use of electronic technology. ${ }^{9}$ At Colorado State University Libraries, they used RLIN, CARL, NOTIS, and a number of CD-ROM products, both indexing and abstracting services (e.g., AGRICOLA, ERIC, MEDLINE) and full-text databases (e.g., CLIMATDATA and HYDRODATA). Ernst and Schmidt concluded that these electronic databases helped them to improve access to government documents and enabled reference librarians to use them more frequently to help library researchers. However, this approach has two major drawbacks. With the exception of the full-text databases, there is no guarantee that a title found in an indexing or abstracting service is actually available in the library's collection. It also should be noted that these electronic databases are not particularly user-friendly and most library users, and even some reference librarians, would find them daunting to use.

Another unorthodox approach to accessing government publications was outlined by C. Diann Weatherly in an article published in $1996 .{ }^{10}$ Her research library, the University of Alabama at Birmingham, chose not to be a federal depository library. Rather, it maintains subscriptions to several microfiche collections (e.g., American Statistics Index, Congressional Index Service, ERIC, all of which have their own indexes for easy retrievability) and other selected subscriptions (e.g., Congressional Record, Commerce Business Daily, and Statistical Abstract of the United States). Weatherly asserted that this library is able to maintain a collection, primarily in microfiche, that is equivalent to roughly 80 percent of available depository titles. Thus, considerable savings in costs for staffing, shelving, binding, and collection analysis/weeding are realized. At the same time, she concluded that service to the university community has been lauded. Short of a careful perusal of the titles included, it is difficult to evaluate the relative merits of the arguments presented in this rather unusual approach to documents collection development.

Relying primarily on microfiche to serve the research needs of library users (for both reference material and titles that normally would circulate for home use) seems unnecessary and might have potentially unfavorable results. Even with the advent of electronic dissemination of information via the Web, one can still appreciate the value of publications in print. Most library researchers would share a preference for materials they can handle and readily browse. Some would seek out alternate titles, available in a paper format, rather than work with titles available only in microfiche.

Only one article, written by Ann Kuntzman in 1995, focused specifically on selectively cataloging federal depository titles. ${ }^{11}$ Adding documents to an OPAC is the best way to improve access to them. Even when they are in a separate CDROM database, Kuntzman argued, few take the extra step in their research to track them down. At the University of Southern Colorado Library, where she is employed, the general collection was becoming outdated as a result of limited book budgets for several years. Because cutbacks in the book budget would not affect a library's participation as a federal depository, GPO titles often emerged as the only reliable source for up-to-date information on a subject.

In describing her efforts to make federal documents accessible, Kuntzman noted that with a professional staff of ten and a limited budget, her options were restricted. Using a commercial vendor to produce a tape of document holdings was prohibitively expensive. In addition, there was considerable concern over the amount of staff time that would be necessary to handle document problems. 
Some document titles on the tape might no longer be owned, were lost or never received, or are duplicates (one record for a paper and one for a fiche copy of a title). Kuntzman also pointed out that, as the only professional librarian handling documents, her time had to be divided with her reference desk duties. ${ }^{12}$

The viable option that Kuntzman chose for her library is selective cataloging. She identified criteria for choosing federal depository titles to be cataloged. They should have reference value, deal with subject matter of current research interest, focus on Colorado, have substantial information, be serials of general interest, or serve as current directories of a field. Documents not considered for cataloging included ephemeral or slight titles and pamphlets, those with outdated information, agency manuals with in-house information, and maps. The cataloging is done using bibliographic records already in the OCLC cataloging system (PRISM service) and, where necessary, original cataloging is input. Each cataloged title is bar coded and a red dot is placed on it.

After one year of selectively cataloging approximately 2,500 documents, Kuntzman reported that the majority of all in-house document titles awaiting reshelving had the red dots and conservatively estimated that at least 70 percent of the documents used were cataloged. She also reported that her reference colleagues were very successful in leading students and faculty to cataloged documents, many of which probably would have been overlooked if left uncataloged and inaccessible in the OPAC. ${ }^{13}$ Kuntzman concluded that for federal depository titles at the University of Southern Colorado Library, "Selective cataloging is proving itself valuable to our library on a daily basis. The results are immediate and satisfying; the costs in dollars and staff are minimal in relation to those results." ${ }^{\prime 14}$

The remainder of this article discusses, in considerable detail, the evaluation process developed by the documents reference librarian at Adelphi University Li- brary for selectively cataloging GPO titles. In addition, the possible use of federal depository titles to enrich a library's permanent research collection, strengthen it where it is weak, and fill in gaps where no other scholarly material is readily available to the library user are examined.

\section{Adelphi As a Federal Depository Library}

Adelphi University is a private university located in Garden City, a residential community in Nassau County, New York. The university has an enrollment of more than 6,000 students, with undergraduate and graduate programs in the liberal arts and sciences, as well as professional schools in banking and business administration, education, nursing, psychological studies, and social work. Adelphi University Library has a collection of more than 450,000 books and bound periodicals. It has been a selective depository since 1966 and currently receives approximately 38 percent of the items available. The documents collection includes approximately 185,000 depository titles in two separate collections, one for paper and the other for microfiche, arranged by SuDoc number. The documents reference librarian has been managing the depository collec-

\section{On rare occasions, students and faculty would ask about new document titles they heard about through the mass media. Even so, the documents collection remained underutilized.}

tion since 1982. As documents reference is a fully integrated component of reference, his primary responsibility is as a reference librarian. Reference assistance in all areas of scholarly endeavor, with the exception of the fine and performing arts and the physical sciences, is provided at the main reference desk by four full-time and several part-time reference librarians.

In 1982, Adelphi switched from a card catalog to an OPAC using CLSI. OPAC terminals are located throughout the library on which searches, using one term 
or Boolean logic, can be conducted. One terminal is kept at the main reference desk. Thus, the documents reference librarian has had ample opportunity to use it. The card catalog was frozen in 1983 and subsequently discarded. A project of retrospective conversion made all cataloged titles accessible through the OPAC (which is called ALICAT [Adelphi LIbrary $C A T a l o g])$ within the next year. Because the CLSI version of ALICAT was not particularly user-friendly (in 1990, Adelphi switched to the much more user-friendly INNOPAC), the reference librarians had to work very closely with many of the faculty and students at the OPAC to help them find titles in the collection.

\section{Selective Cataloging at Adelphi}

Two of the major responsibilities of the documents reference librarian are to improve access to the federal depository collection and to ensure that it reflects the needs of the Adelphi community. With this in mind, the first major project undertaken by the incumbent was a systematic review of the titles being received under the item numbers chosen as a selective depository in 1982. The documents reference librarian was concerned that significant research titles in the documents collection were rarely used by students and faculty. The need to make them more readily accessible was evident. An annotated bibliography of significant new titles, What's New in Documents, was prepared and distributed annually with the hope of drawing attention to this collection. Moreover, faculty members were contacted whenever the documents reference librarian came across a title that might be of interest to scholars in their discipline. On rare occasions, students and faculty would ask about new document titles they heard about through the mass media. Even so, the documents collection remained underutilized. This was evidenced by the fact that, prior to 1982 , the circulation figures for federal depository titles, which have to be manually charged out for home use when they are not cataloged, were miniscule (i.e., so few that it was unnecessary to maintain statistics for them).

In reviewing significant new document titles, the documents reference librarian often discovered that few, if any, recent titles were in the OPAC on the same subject. In such instances, by cataloging federal depository titles the library's collection could be strengthened where it was weak or gaps, where private sector publications either did not exist or had not been acquired by Adelphi, could be filled. For popular research topics, even if the OPAC already had a large number of cataloged titles, adding depository titles could broaden the selection of available research titles in that area. For series that Adelphi was receiving primarily in microfiche (e.g., congressional hearings and committee reports), if the title were worth cataloging, an additional copy could be purchased in paper, if available, and could be cataloged as well. The documents reference librarian was, after all, mindful of the preference of library researchers to work with titles in a paper format. Ultimately, it was determined that selectively cataloging federal depository titles was an innovation worth pursuing.

At Adelphi, INNOVACQ is used to check in all federal documents received. ${ }^{15}$ Library users can find listings for all titles received because a holdings record exists for all SuDocs classifications for which titles are received. However, unless the title is catalogued individually, library users must search by the Superintendent of Documents classification series (e.g., ED 1.2, HE 20.3165, and J28.2) and then review the check-in record to find out if the library has the title needed. By selectively cataloging federal depository titles, they would be fully accessible by author, title, and subject.

Because of the nature of reference services at Adelphi, the documents reference librarian was interested in providing only selective access to federal depository titles in the library's OPAC. Working with students, faculty, and other members of the Adelphi community in all areas of scholarly endeavor, the emphasis in providing 
reference services is on scholarly research. More ephemeral titles could still be accessed through CD-ROM indexing and abstracting services, especially the GPO on SilverPlatter, as well as increasingly through the Internet in the past few years. In addition, two other types of publications are cataloged at Adelphi. In consideration of their reference value, the most recent editions of directories are cataloged. Those periodical titles that are readily accessible in the indexing and abstracting services also are cataloged because of their research value. Being able to draw the attention of library users to invaluable reference and research titles available in Adelphi's depository collection and making them readily accessible in the OPAC is the goal.

The retrospective cataloging of all federal depository titles received at Adelphi was never considered seriously. The cost, both financially and in terms of labor, seemed prohibitive for a collection of 185,000 titles. Most of the titles are either too ephemeral or too esoteric or specialized to be of interest to most library researchers. As has already been mentioned, these titles could still be accessed in the CD-ROM indexes and abstracting services. Another consideration is the experience of the documents reference librarian who, as part of the normal weeding procedure of a selective depository collection, was discarding more than 95 percent of the titles received after the five years that the library was legally mandated to keep them. If these titles were in the OPAC, they would have to be purged after five years.

\section{Development of Review Criteria}

After it was decided to catalog only selected titles, review criteria were developed. The major criterion is whether a title fills a gap in the collection or strengthens the collection in an area where it is weak (i.e., where the library has five or fewer titles published in the past five years in the OPAC on that subject). The documents reference librarian developed a procedure involving ALICAT searching to determine what titles to catalog. Certain classes of documents (e.g., general publications and bibliographies and lists of publications) proved to be more promising and were designated for selective cataloging review. This meant that all new titles received in these series, with the exception of slight (i.e., containing fewer than twenty pages) titles or pamphlets, are routed to the documents reference librarian for a cataloging decision. If a title received in a series that is not normally reviewed for cataloging decisions (e.g., handbooks, manuals, guides, or maps) catches the eye of the documents clerical assistant, who checks them in INNOVACQ, it is brought to the attention of the documents reference librarian. In addition, the first time a title is received under a new SuDocs number, it is reviewed to determine whether it should be cataloged and whether all titles in this series should be reviewed.

If a federal depository title seems substantial enough to warrant consideration, a search, using Library of Congress subject headings and/or keywords, is conducted in ALICAT. Usually, each search can be conducted in as little as one minute. But it may take as much as five minutes to review a more complex title and develop an appropriate search strategy (e.g., using Boolean logic to link two subjects). Most searches are conducted when the documents reference librarian is scheduled to be working at the library's main reference desk, whenever there are no library users at the desk requesting reference assistance. As a result, it is unnecessary to allot specific time to work solely on this project.

Over the course of the past ten years, as a result of budgetary restraints at Adelphi, the library's book acquisitions budget has been frozen, reduced, or cut off completely at different times. Thus, as a result of applying these criteria, there are numerous instances where cataloged federal documents are very prominent among the most recent titles accessible in the library's OPAC or the only ones available. For example, all cataloged holdings 
published after 1990 on the following subjects are depository titles:

- Cardiovascular System-Diseases-Prevention;

- Community Policing;

- Drug abuse-United States-Statistics;

- Electronic Surveillance;

- Methadone Maintenance;

- Prisoners-United States-Statistics;

- Shock Incarceration;

- Youth-United States-Drug Use.

In these and other subject areas, federal depository titles are filling in a gap where the book collection is weak and have emerged as the most reliable source of comprehensive and up-to-date information.

Occasionally, a federal depository title covers two diverse subjects in a way that no other cataloged title in Adelphi's collection does. For these titles a Boolean search is conducted using both subjects. For example, there are documents evaluating drug abuse treatment programs for prison inmates. A subject search for "Prisoners" is done, and the results are limited by inputting a second subject, "Drug Abuse-Treatment." As a result, the library now has three cataloged titles linking both of these subjects in the OPAC, all of which are federal depository titles. Another example is that of document titles covering crime prevention in public housing projects. A subject search for "Public Housing" is limited with a second subject, "Crime Prevention." For these two linked subjects, as well, the only "hits" in the OPAC are federal documents.

Keyword searching can be very helpful when there is uncertainty about the appropriate Library of Congress (LC) subject heading or if there is none covering a specific title. A keyword search also can lead to other titles with the subject heading needed. For example, a search under the keyword "glass ceiling" (which is not a LC subject heading) leads to titles with appropriate LC subject headings, including "Sex Discrimination in Employment" and "Women-Employment." A Boolean search limited to both these subjects then would reveal if any cataloged titles linking these two subjects are in the OPAC. Keyword searching may thus help identify federal depository titles worthy of cataloging, either because they fill a gap in the collection or strengthen it where it is weak in the OPAC.

In some cases, a title may be cataloged even if five or more titles on the same subject already have been cataloged in the past five years. This practice is followed for very popular subjects (e.g., education, bilingual, gun control, or smoking) or if the new document title is very comprehensive (e.g., a multivolume evaluation of programs to combat poverty).

A title being considered for cataloging should reflect and support the needs of the library users. For this reason, if the documents reference librarian feels that a title is too exotic or esoteric for the Adelphi community (e.g., a collection of essays on opioid peptides or a review of renewable resources on U.S.- affiliated tropical islands), it is not cataloged. There is no need to catalog depository titles that a library's clientele are unlikely to use. Thus, engineering titles are unlikely to be cataloged because Adelphi does not have an engineering program. In instances where the documents reference librarian is unfamiliar with a subject area and does not feel capable of making a fair evaluation, the title is referred to the library specialist for that subject.

Even if an important title "slips through the cracks" and is not cataloged, library users still have access to it through the GPO on SilverPlatter, one of the CDROM databases available at Adelphi. Using the Superintendent of Documents series number, users can check ALICAT to find out whether the library receives titles in this series. The holdings record will show if the title has been received. However, there are drawbacks to relying too heavily on this electronic database to track down materials for library users. GPO on SilverPlatter is not a catalog of the library's holdings. The title found might be part of a series not chosen by a selective de- 
pository. The titles in this database may be as old as 1976, and the holdings of most selective depositories go back about five years for most series. Waiting a few weeks to obtain the title via interlibrary loan may not be feasible for some library users. Moreover, for most subjects the older a title is, the less useful its material.

In reviewing "old-timers" (i.e., federal depository titles received more than five years ago) for weeding and discarding decisions, the documents reference librarian can be even more selective in choosing titles for cataloging. Potential discards include those titles in a reviewed series that the documents reference librarian decided not to catalog when they were new. In addition, most of the old-timers are from series that would not normally be reviewed for cataloging decisions when they came in. In either case, the documents reference librarian now has an opportunity to review these titles (assuming they are not outdated) for cataloging consideration. However, the main library at Adelphi is so crowded that there is no room for any substantial increase in the size of the collection. Off-campus storage seemed impractical because library users would have to wait several days for the material to be retrieved.

Thus, the same basic criteria for reviewing new titles are used for those that are more than five years old when the latter are reviewed for discarding-versuscataloging decisions. To determine whether potentially interesting titles are worth cataloging, subject and keyword searches are conducted in ALICAT. For example, if a potentially valuable title was received in 1993, it is important to find out whether the library has five or more additional titles on the same subject, published either in that year or more recently.

For this project to be successful, the cooperation of catalogers, who are responsible for providing full access in the OPAC, and their staff, who must label and process the cataloged titles, was necessary. The documents reference librarian at Adelphi was fortunate to receive this cooperation. In most instances, the cata- logers are able to use bibliographic records already in the OCLC database. Thus, these titles are made fully accessible in ALICAT. At the outset, it was decided to leave the titles classified by the SuDocs number in the documents collection in order to draw the attention of library users to the wealth of information available there. Most government documents, including those selected for cataloging, circulate for home use. Uncataloged document titles returning from circulation are likely candidates for cataloging consideration. After a document title has been cataloged, it is zebra-labeled (to expedite borrowing for home use) and stamped (so that it is not inadvertently discarded as part of the normal weeding of the documents collection) as follows:

\section{ADELPHI UNIVERSITY LIBRARY DOCUMENTS COLLECTION CATALOGED-DONOT DISCARD}

After a federal depository title is fully cataloged, it is likely to remain a part of the library's permanent collection, with few exceptions, the same way that privately published books are.

\section{Positive Impact of Selectively Cataloging Document Titles}

Although no systematic study has been undertaken to confirm the positive impact of selectively cataloging federal depository titles at Adelphi, it is obvious at the reference desk. However, it can be reported that circulation records in ALICAT for more than a thousand cataloged GPO titles have been charged out at least once, and as many as twenty-nine times, as of November 1999. Working with students and faculty, the reference librarians frequently are finding document titles in the OPAC to answer a difficult reference query. Occasionally, the only recent titles found are cataloged federal depository ones. In retrieving some of these titles in the document stacks, it is not uncommon for library users to find additional titles of value shelved nearby. After reviewing 
the document titles found, students and faculty often express amazement that the federal government publishes such comprehensive works on a subject. It is especially gratifying when library users report finding material in an area where they would have never thought to look-the federal depository collection.

For all of these reasons, selective cataloging of federal documents has had a positive impact at Adelphi. The use of an OPAC, in which subject and keyword searching can be done, has been instru- mental in filling gaps in the library's permanent research collection and strengthening it where it was weak. One of the most important purposes of the federal depository program is making information more readily available to the public. Cataloging significant depository titles makes them more readily accessible to the library user and more valuable library assets. Therefore, selectively cataloging federal document titles using an OPAC can be strongly recommended to all depository libraries.

\section{Notes}

1. Marilyn K. Moody, "Source of First Resort," Library Journal 117 (May 15, 1992): 36.

2. Mary Redmond, "From Backwater to Mainstream: Government Documents in the Online Catalog," Booklist 47 (spring 1989): 161-65. Also available as part of an ERIC document (ED 326 239).

3. Stanley P. Hodge, Diane Calvin, and Galen E. Rike, "Formulating an Integrated Library Government Documents Collection Policy," Government Information Quarterly 6 (May 1989): 199. This article includes an appendix for matching federal agencies and subject areas on pages 20412.

4. Naomi V. Kerze, "Separate vs. Integrated: The Disappearing Debate over the Organization of United States Government Publications in Depository Libraries," Government Publications Review 16 (Sept. 1989): 439-45.

5. Liz C. Alexander, "Issues in Government Information and Technology," Illinois Libraries 76 (summer 1994): 161.

6. Margaret T. Mooney, "Matching Library Holdings against GPO Tapes: Issues, Concerns, and Solutions," Government Publications Review 17 (Sept. 1990): 421-28.

7. Myrtle Smith Bolner and Barbara Kile, "Documents to the People-Access through the Automated Catalog," Government Publications Review 18 (Jan./Feb. 1991): 51-63.

8. Thomas Kinney and Gary Cornwell, "GPO Cataloging Records in the Online Catalog: Implications for the Reference Librarian," Reference Librarian 32 (1991): 259-75.

9. Douglas J. Ernst and Fred C. Schmidt, "Computerized Access to Government Publications at Colorado State University Libraries," Reference Librarian 32 (1991): 277-88.

10. C. Diann Weatherly, "A U.S. Government Publications Collection in a Non-Depository Research Library: A Case Study," Journal of Government Information 23 (July/Aug. 1996): 471-89.

11. Ann Kuntzman, "Selective Cataloging of Federal Documents: A Good Way to Increase Access," College $\mathcal{E}$ Undergraduate Libraries 2 (1995): 111-19.

12. Ibid., 112-13.

13. Ibid., 113-18.

14. Ibid., 119.

15. Based on Adelphi's experience with INNOVACQ and federal depository titles, a manual was prepared and subsequently published as an ERIC document: Victor T. Oliva and Michael K. Reiner, Using INNOVACQ to Process G.P.O. Titles, ED 316 195, 1989. 